\title{
Song post exposure, song features, and predation risk
}

\author{
A. P. Møller, ${ }^{a}$ J. T. Nielsen, ${ }^{b}$ and L. Z. Garamszegic ${ }^{c}$ \\ ${ }^{a}$ Laboratoire de Parasitologie Evolutive, CNRS UMR 7103, Université Pierre et Marie Curie, Bât. A, \\ 7ème étage, 7 quai St. Bernard, Case 237, F-75252 Paris Cedex 05, France, ${ }^{b}$ Espedal 4, Tolne, DK-9870 \\ Sindal, Denmark, and ${ }^{\mathrm{C}}$ Department of Biology, University of Antwerp, Campus Drie Eiken, \\ Universiteitsplein 1, B-2610 Wilrijk, Belgium
}

\begin{abstract}
Male birds use song to attract mates and deter other males, but in doing so, they also attract the attention of predators and parasites. Such viability costs are inherent in reliable signals, potentially causing females to prefer mates that display from the most exposed sites. However, viability costs of sexual signals may be ameliorated by affecting the choice of microhabitat, which in turn may affect the design of song features that are most efficiently transmitted in this microhabitat. We estimated the exposure of song posts (microsites used by males when singing) used by passerine birds in relation to prey selection by the sparrowhawk Accipiter nisus, by calculating the proportion of males that sang from song posts that were at the maximum level of the vegetation, in an attempt to quantify the costs of sexual selection. We quantified prey susceptibility to predation as the difference between the log-transformed observed number of prey minus the log-transformed expected number of prey in the environment. This prey susceptibility index increased with increasing song post exposure similarly in sexually dichromatic and monochromatic species, although the prey susceptibility index was related to sexual dichromatism. Song post exposure was dependent on habitat, but comparative models controlling for the potentially confounding effects of habitat, sexual dichromatism, hole nesting, coloniality, body mass, cognitive capacities, and flying abilities indicated that the relationship between the prey susceptibility index and song post exposure is strong. Path analyses of the relationship between song post exposure, sexual dichromatism, and prey susceptibility index revealed that selection acting on sexual dichromatism and song post exposure has secondary impact on prey susceptibility index. The opposite causal mechanisms by which predation affects sexual traits are less likely. These models suggest that female preference for high song posts or dichromatic plumage increases predation risk on an evolutionary time scale. Key words: birds, costs of sexual selection, prey selection, sound transmission. [Behav Ecol]
\end{abstract}

$\mathrm{S}^{\mathrm{e}}$ exual selection results in the evolution of exaggerated signals that provide their bearers with an advantage in terms of mating in competition with conspecifics but also a viability cost in terms of increased risk of parasitism, predation, or loss of time and energy (Andersson, 1994; Darwin, 1871). Therefore, signalers have to optimize transmission of signals while avoiding the viability costs. Sexual display causes an increase in levels of parasitism due to the effects of display on immunity and other antiparasite defenses (Møller et al., 1999). Studies of brood parasitism have shown that bird species with extravagant feather ornamentation and with certain vocal displays run elevated risks of being parasitized (Garamszegi and Aviles, 2005). Likewise, a large number of studies have shown that exaggerated signals increase the risk of predation (Zuk and Kolluru, 1998). While such costs have been demonstrated in a number of elegant experiments (e.g., Cade, 1975), there is little information on the factors that determine interspecific variation in the magnitude of such costs (see Garamszegi and Avilés [2005] for an exception).

Costly signals reliably reflect the quality of a sender because the differential cost of exaggerated traits prevents low-quality individuals from producing the largest signals (Zahavi, 1975), providing a general explanation for the reliability of signals (Grafen, 1990). Therefore, females may prefer to mate with males that run higher risks of parasitism or predation because

Address correspondence to A. P. Møller. E-mail: amoller@snv. jussieu.fr.

Received 15 April 2004; revised 22 February 2005; accepted 25 September 2005.

(C) The Author 2005. Published by Oxford University Press on behalf of the International Society for Behavioral Ecology. All rights reserved.

For permissions, please e-mail: journals.permissions@oxfordjournals.org only high-quality individuals will be able to carry such costs. If sexual signals are costly to produce and maintain, there is feedback on the design of signals to remove or alleviate such costs (e.g., Møller, 1996). Therefore, we should expect viability costs of signals to result in a modification of these signals so that they could only be located with difficulty by predators, as suggested for certain vocal signals (Brown, 1982; Marler, 1955; but see Shatler, 1978). However, such modifications may be at conflict with the features of the signal that promote its effectiveness in attraction of mates. We might even expect females to cue in on sexual signals that were particularly costly because only high-quality males will be able to produce such signals, thereby enforcing reliability of the information content of the signal. Likewise, we might expect that choice of signaling environment may increase the risk of predation causing feedback on habitat selection. Again, we might expect coevolutionary interactions between sender, receiver, and predator because a predator-safe microsite may be unsuitable for the production of attractive signals. Receivers might differentially respond to males that produce songs in exposed sites, causing antagonistic selection pressures on choice of microsite due to the effects of predators and receivers. These implications should also be considered in the context of transmission of vocal signals in the environment. Different habitats have different transmission properties (e.g., Slabbekoorn and Smith, 2002; Wiley and Richards, 1982), and vocal signals show design features that suggest that they have been modified to facilitate efficient transmission in particular habitats (e.g., Slabbekoorn and Smith, 2002; Wiley and Richards, 1982). Previous studies of choice of microsite for singing suggest that a higher position in the vegetation does not necessarily benefit transmission of sound but may facilitate perception 
(e.g., Dabelsteen et al., 1993; Holland et al., 1998). Song post may be expected to be sensitive to selection as the combined cost of production and thermoregulation at exposed song posts can represent a significant energetic cost (Ward and Slater, 2004).

Bird song constitutes a classical example of a secondary sexual character used both in a mate choice and a male-male competition context (Darwin, 1871). Currently, there is little evidence of predation affecting the design of vocal signals in birds (Hale, 2004; Mougeot and Bretagnolle, 2000). This is in sharp contrast to what has been shown for plumage traits in birds (Götmark, 1993; Martin and Badyaev, 1996) or for songs of anurans and insects, where numerous cases of predation have been reported (Zuk and Kolluru, 1998). We consider the scarcity of reports on predation of singing birds to be an artifact of the lack of specific studies designed to test this hypothesis. As shown in the present study, there is clear evidence of relationships between exposure of microsites used for singing, song features, and relative predation risk to an avian predator among common passerine birds. Such relationships would seem unlikely to have evolved unless predation in the past and currently was an importance force of natural selection.

We investigated prey selection by the European sparrowhawk, which is the most common avian predator in forested regions of the Palearctic. The main prey species of this sexually size dimorphic predator are tits, thrushes, finches, buntings, and sparrows (Newton, 1986). The cues used by sparrowhawks to select prey are unknown, but based on our own extensive field experience they use both visual and acoustic cues for finding avian prey. Male sparrowhawks catch all food for the egg laying, incubating, and brooding female until the nestlings have reached an age of 3 weeks, and they also provide most of the food for older nestlings (Newton, 1986). Prey is plucked at traditional sites close to the nest, from where it is transported to the nest, providing us with easy access to prey remains.

The aims of this study were to investigate the interactions between relative predation risk, song post choice, and song features, using common European passerine birds and predation by the sparrowhawk Accipiter nisus as a model system. By song post, we mean the microsite used when singing. First, we tested the prediction that greater exposure of song posts was associated with an increase in relative risk of predation. Second, we investigated the relationship between susceptibility to predation and song features of different species of birds under the assumption that predation pressure has modified song to reduce viability costs of specific features. Third, we investigated a number of different alternative causal models explaining the relationship between relative predation risk, song post choice, and song features using path analysis as a tool. Basically, we investigated the degree of fit of alternative hypothetical relationships between the three kinds of variables. We used sexual dichromatism as an additional variable in all these analyses because sex differences in coloration is well known for being involved in sexual selection (Darwin, 1871), opening the possibility that it could constitute an important confounding variable.

\section{METHODS}

\section{Study area and sample size}

Nielsen (2004a) studied European sparrowhawks in two areas of 68 and $436 \mathrm{~km}^{2}$ in Northern Denmark. Prey remains of the European sparrowhawk were systematically collected near nest sites during the months April-September 1978-1997 from 1709 nests. A total of 31,745 prey items of 66 species of passerines and near passerines from terrestrial habitats were used for the present analyses, while 3178 prey items were excluded because they were mammals or cage birds. The relative abundance of prey was highly repeatable in different areas and in different years, showing a high degree of spatial and temporal consistency (Møller AP, unpublished data).

We do not consider it likely that we erroneously allocated prey to the European sparrowhawk. The goshawk Accipiter gentilis is also a major predator on birds, although it generally preys on much larger species than the sparrowhawk. J.T.N. is very familiar with the goshawk and its prey after having studied the breeding population for 27 years. Prey is usually plucked near the nest site, making mistakes unlikely. Furthermore, the goshawk usually removes many feathers simultaneously, while the European sparrowhawk only removes single primaries or secondaries at a time (Opdam, 1978; van Beusekom, 1972). Finally, almost all prey were located directly on nests of the European sparrowhawk. Therefore, we assume that prey has been allocated reliably to the sparrowhawk. A second potential source of bias is that not all prey species are equally likely to be found. In this study, we only included prey remains when they were judged to be less than 1 month old.

\section{Estimating prey selection}

We calculated the expected number of prey of a given species by using information on density of breeding birds obtained from systematic randomly chosen point counts throughout Denmark (Grell, 1998). Maps of the density of breeding birds have been made based on systematic point counts of breeding birds by hundreds of amateurs, and the mean density of breeding birds in the study areas of Nielsen (2004a) was extracted from Grell (1998). Such point counts provide reliable estimates of the density of breeding birds as shown by extensive analyses of potential sources of error and bias (see justification for this conclusion in Grell, 1998). For five species for which quantitative information on population density was not provided on maps, we estimated the population density by using the mean estimate of the total population size for Denmark for the most closely related species with quantitative information and the species without such information, from Grell (1998). These two estimates of total population size and the single estimate of population density allowed us to estimate the population density of the species with missing graphical information. Thus, if species A had a density of 0.50 and if species A and B had total population sizes of 100,000 and 50,000, then the density for species B was estimated as $0.50 \times(50,000 / 100,000)=$ 0.25 . The exclusion of these five species with estimated population density did not change the results. The minimum density value used was 0.001 individuals recorded per point.

We designed an index of prey susceptibility to predation as the $\log _{10}$-transformed observed number of prey minus the $\log _{10}$-transformed expected number of prey. The expected number was estimated from the combined density of all species, the total number of prey items, and the proportion of prey items of each species. This index has a value of zero when prey items are represented according to their abundance, while positive values signify an overrepresentation relative to the abundance and negative values an underrepresentation. As an example, consider the tree sparrow Passer montanus with 2479 individuals being found as prey out of 31,745 prey individuals. The expected number of prey was the density of the species (which was 0.33 out of a total density of all species of 13.72) divided by total density and multiplied by the total number of prey, or $(0.33 / 13.72) \times 31,745=765$. The prey susceptibility index for the tree sparrow is then $\log _{10}(2479)-$ $\log _{10}(765)=3.394-2.884=0.51$.

\section{Estimating song post exposure and features of song}

We estimated song post exposure by determining the height of the song post of common passerine birds during 1986-1989 
relative to the surrounding vegetation or structures such as buildings. One of us (A.P.M.) systematically noted the height of all song posts recorded during March-August whenever in the field. Although mate choice may mainly occur during spring, choice of extrapair copulation partners may continue throughout the summer when second and third clutches are fertilized. Hence, the time windows for assessment of song post and assessment of prey selection overlapped. We only considered the vegetation within a distance of $2 \mathrm{~m}$ from the singing bird. In brief, song post exposure is estimated as the percentage of all song posts of a given species that are at a height above the surrounding vegetation, ranging from 0 when all song posts are lower than the surrounding vegetation to 100 when all song posts are above the vegetation. The number of observations on which each of these estimates for a different species was based ranged from 28 to 500 song posts. This method for describing song posts was first developed by Scherrer (1972), who reported quantitative information for 34 common species. There was a high degree of consistency in song post exposure between the present study and that of Scherrer (1972), based on the 22 species for which there was information for both studies $(F=479.69$, df $=$ $21,22, p<.001)$. This analysis indicates that there is little geographic variation in song post exposure and that song post exposure was estimated in a repeatable and hence reliable way. The significant repeatability of the trait also shows that seasonal variation in song post seems to be negligible when compared to variation among species.

To characterize the complexity and temporal organization of songs in different species, we used reported song duration (in s), intersong interval (in s), and song type and syllable repertoire size from the literature. Use of song parameters in comparative analyses raise issues about comparability (Krebs and Kroodsma, 1980). We have previously investigated the extent to which different measures of song complexity and temporal organization provide reliable and comparable information (Garamszegi and Møller, 2004; Garamszegi et al., 2003). Using a number of different tests, we found a high degree of consistency among comparable measures of complexity, justifying our approach (see Garamszegi and Møller [2004] and Garamszegi et al. [2003] for details). Finally, the fact that previous comparative studies of song features in birds have shown biologically meaningful results (Badyaev et al., 2002; Read and Weary, 1992; Székely et al., 1996) suggests that song complexity and temporal organization indeed provide reliable information. We primarily used song data from Read and Weary (1992) that was supplemented with information from other sources (Bell et al., 2004; Cramp and Perrins, 1985-1994; Cucco and Malacarne, 1999; Greig-Smith, 1982a,b; Güttinger, 1977; Kunc et al., 2005; Lampe and Espmark, 1994; Matessi et al., 2000; Mota and Cardoso, 2001; Naguib and Kolb, 1992; Singer and Nicolai, 1990; Thielcke and Wüstenberg, 1985; Von Gerss, 1989; ). Analyses of reliability showed that these features of song are repeatable within species (Garamszegi and Møller, 2004).

\section{Phenotypic characteristics of prey species}

We scored prey species as sexually monochromatic or dichromatic. Monochromatic species were given a score of zero, if males and females were indistinguishable from each other based on plumage characters shown in field guides (e.g., Mullarney et al., 2000; Svensson, 1984). Any sex difference in plumage coloration independent of its magnitude was considered to represent sexual dichromatism, which was scored as one. We did not quantify the magnitude of the sex difference in coloration because we do not know how predators perceive such differences. However, our dichotomous score used here was strongly positively correlated with quantitative scores reported by Møller and Birkhead (1994) and Read (1987), suggesting that dichotomous scores and continuous scores provide similar information.

Song post height may depend on the density of the habitat (Scherrer, 1972). Furthermore, the sparrowhawk may prefer woodland edges for hunting (Cramp and Simmonds, 1979), and such habitat preferences may induce an interspecific association between song post and prey selection. Therefore, we scored the breeding habitat of all species on a three-point scale, where 0 equals grassland, 1 bush and scrub, and 2 forest.

Larger species may provide more resources to predators, but may be more difficult to catch, while very small species may be unprofitable. Götmark and Post (1996) showed that sparrowhawks prefer prey of intermediate size, with a bell-shaped relationship between preference and body mass. Therefore, we used mean body mass and squared mean body mass as predictor variables based on our own field measurements, or in the absence of data as reported by Dunning (1993).

Birds that are better at escaping the sparrowhawk may be less represented in its diet. For example, predator avoidance may be associated with cognition and learning, and birds better at learning the complex task of predator avoidance may experience lower rate of predation. Similarly, flying ability may also reflect predator avoidance, and predators may less frequently capture species that are better at maneuvring in the air (Götmark and Post, 1996). Therefore, we used relative brain size to estimate the importance of cognition (as done in other studies [Garamszegi and Eens, 2004; Iwaniuk and Nelson, 2003]) and relative wing length to assess flying ability. The control for body size was achieved in multiple regression models that included wing length and brain size together with body mass. We predicted that birds with larger brains and longer wings relative to their body size have a lower prey susceptibility index due to successful predator avoidance than others with smaller brains and shorter wings for their body mass. Brain mass data were taken from Mlíkovsky (1990), Iwaniuk and Nelson (2003), and Garamszegi et al. (2002), whereas information on wing length originated from Cramp and Perrins (1985-1994).

Sparrowhawks may prefer certain prey for nutritional reasons that may also produce confounding effects. To estimate the nutritional value of different birds, we used relative liver mass and relative heart mass from Møller et al. (2005). The liver and the heart are metabolically important organs as they play crucial roles in circulation, digestion, and assimilation. The size of these organs may potentially correlate with nutritional traits (e.g., protein content) that importantly affect the sparrowhawk's prey preference.

We also controlled for the potentially confounding effect of nesting habits because hole-nesting birds may be hidden for considerable amounts of time inside nest holes. In addition, the aggregated distribution of prey may also affect predation rate. Conspicuous colonial breeding sites may be attractive to predators, or potential prey may evolve more efficient defenses against their enemies by means of different social behavior. Accordingly, we assessed the effect of hole nesting and coloniality by using two-point scales. For hole nesting, 0 represents breeders of open nests, whereas 1 stands for hole-nesting species. For coloniality, we assigned 0 to solitary breeders and 1 to colonial breeders. Data were obtained from Cramp and Perrins (1985-1994).

All the data are reported in the electronic appendix.

\section{Comparative analyses}

We tested the predictions by analyzing statistically independent linear contrasts to control for similarity in phenotype 


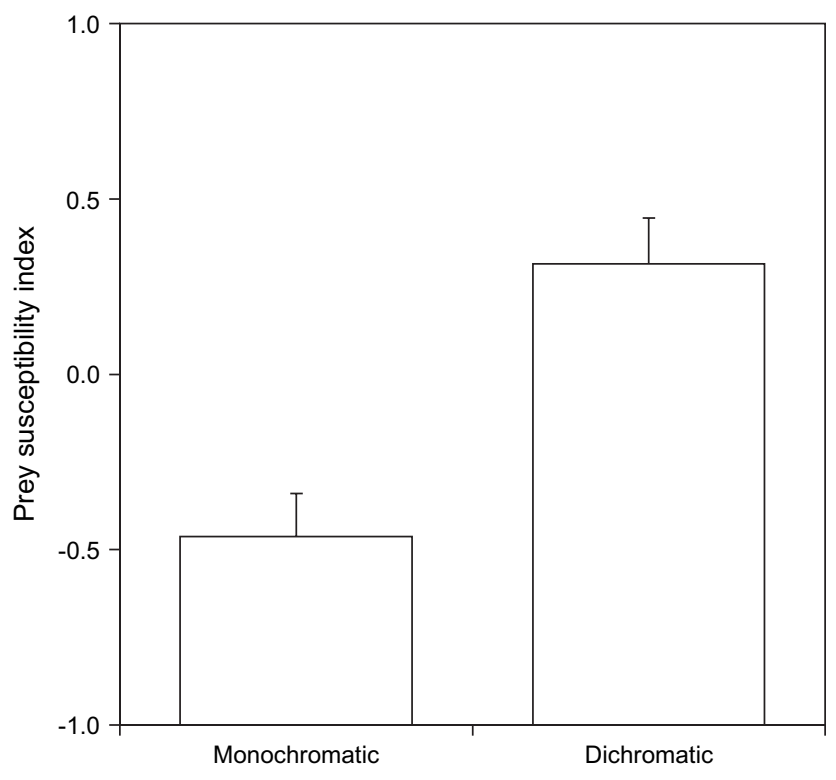

Figure 1

The relationship between prey susceptibility index and sexual dichromatism among birds, when analyses are based on the raw species data. Histograms are means and error bars standard errors ( $N=66$, with 35 monochromatic and 31 dichromatic species).

among species due to common descent (Felsenstein, 1985), using the computer program CAIC (Purvis and Rambaut, 1995). We tested the statistical and evolutionary assumptions of the continuous comparative procedure by regressing absolute standardized contrasts against their standard deviations (Garland et al., 1992). In order to reduce problems of heterogeneity of variance, we excluded outliers (contrasts with studentized residuals $>3$ ) from subsequent analyses (Jones and Purvis, 1997). However, the analyses relying on the entire set of contrasts provide very similar results. Similarly, the findings and the conclusions did not change, if we tested for phylogenetic associations based on the nonparametric correlations of the contrasts.

We used a composite phylogeny in the analyses based on Sibley and Ahlquist (1990), combined with other sources (Badyaev, 1997; Barker et al., 2001; Blondel et al., 1996; Cibois and Pasquet, 1999; Møller et al., 2001; Sheldon et al., 1992; Slikas et al., 1996). We applied branch lengths from the tapestry tree of Sibley and Ahlquist (1990) for higher taxonomic levels (above family levels). Within families, the distance between different genera was set to $3.4 \Delta \mathrm{T}_{50} \mathrm{H}$ units, and we used $1.1 \Delta \mathrm{T}_{50} \mathrm{H}$ units between species within genera. The entire phylogeny is given in Figure 1 in the electronic appendix.

Body mass, brain mass, wing length, song duration, intersong interval, and syllable and song type repertoire size were $\log _{10}$ transformed, whereas song post height was square root arcsine transformed before analyses. Coded variables were treated in a continuous scale in our analysis. The statistical reason behind this choice is that although these variables may appear discrete, intermediate states are biologically meaningful, and different states are thus arbitrary points along a continuum (Sokal and Rohlf, 1995: 11-12). In addition, in an evolutionary context, a transition between two states of these variables follows nondiscrete evolutionary changes. Therefore, the continuous treatment is generally applied in comparative studies that are constrained to use qualitative data for a larger set of species (e.g., Bennett and Owens, 2002; Harvey and Pagel, 1991). Thus, as a result, one can show qualitatively that a given trait plays a role in the evolution of another but cannot
Table 1

The phylogenetic relationship between prey susceptibility index and hole nesting, coloniality, habitat type, and sexual dichromatism as assessed by continuous (Crunch) and discrete (Brunch) approaches

Variable Crunch Brunch

\begin{tabular}{lll}
\hline Hole nesting & $F_{1,53}=0.15, p=.70$ & $t_{12}=0.38, p=.71$ \\
Habitat type & $F_{1,51}=0.05, p=.83$ & $t_{12}=0.09, p=.93$ \\
Coloniality & $F_{1,54}=1.38, p=.24$ & $t_{5}=0.39, p=.71$ \\
Sexual dichromatism & $F_{1,53}=9.51, p=.003$ & $t_{15}=3.37, p=.004$ \\
\hline
\end{tabular}

To achieve bivariate distribution for habitat type, we collapsed the three categories into two categories (by pooling categories 0 and 1 as this solution gives the maximum number of contrasts).

assess its quantitative importance. This procedure was further justified by a comparison of results based on continuous and discrete approaches using the Crunch and Brunch procedures of CAIC. The Crunch algorithm assumes that the variables in focus have continuous distribution. On the other hand, the Brunch approach is based on the assumption that the independent variable is discrete. Comparisons of the same phylogenetic associations as assessed by Crunch and Brunch approaches revealed very similar conclusions (Table 1).

We used stepwise linear regressions through the origin to find the best-fit model using the phylogenetically independent contrasts for the predictor variables. We forced regressions based on contrasts through the origin because comparative analyses assume no evolutionary change in a character when the predictor variable has not changed (Purvis and Rambaut, 1995). We investigated the effects of both forward and backward elimination procedures to determine the stability of findings, and none of the final models differed when comparing forward and backward elimination models, suggesting that the conclusions were robust. We identified the best-fit model using Akaike's information criterion of different models as an estimate of the improvement in fit for addition of variables (Burnham and Anderson, 1998). There was no evidence of strong collinearity between variables, with all correlations being less than 0.70. Green (1979) suggested that collinearity is not a problem under these conditions.

We investigated the relationships between song post exposure, sexual dichromatism, and predation risk using path analysis (Li, 1975; Wright, 1968) because the different variables may be related to each other in different ways. In a first series of analyses, we investigated how song post exposure and sexual dichromatism could affect predation risk either through direct effects or by an interacting effect. In a second series of analyses, we investigated how from a sexual selection perspective predation risk might affect song post exposure and sexual dichromatism and if covariation between the two song features was independent or caused by predation risk being an intermediary variable.

We had information on a total of 75 species for the prey selection index or song post exposure. However, the number of species varied among analyses because data on prey susceptibility or song post exposure were unavailable for all species and also because we deleted outliers prior to analyses. For illustrative purposes, relationships based on the raw species data are also presented, but all reported statistics are for phylogenetically independent contrasts.

\section{RESULTS}

\section{Prey selection and song post exposure}

Bird species with a larger prey susceptibility index had more exposed song posts (Figure $2 ; F_{1,40}=7.85, p=.008$ ). We 

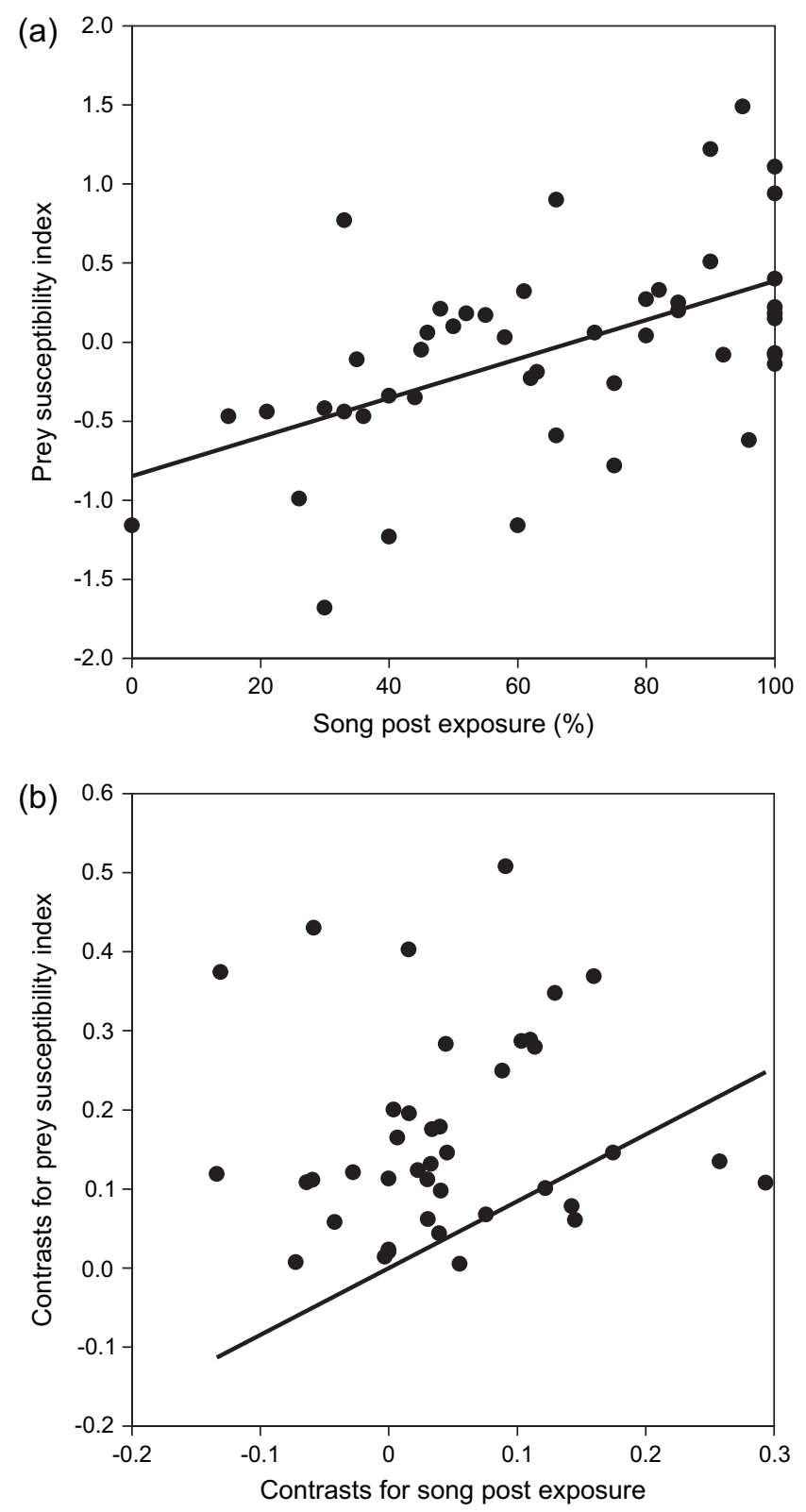

Figure 2

Prey susceptibility index by the sparrowhawk in relation to song post exposure of 48 bird species. The lines are linear regression lines (a) when using raw species data and (b) when using statistically and phylogenetically independent contrasts.

found that prey selection was associated with sexual dichromatism as sexually dichromatic species appeared to be depredated more frequently than monochromatic species (Table 1 and Figure 1). However, there was no significant association between song post exposure and sexual dichromatism $\left(t_{14}=-0.43\right.$, $p=.67)$. In addition, the relationship between prey susceptibility index and song post exposure was independent when we controlled for sexual dichromatism. When we analyzed dichromatic and monochromatic species separately, we found highly significant associations between prey susceptibility index and song post exposure in both samples with similar slopes (monochromatic species: $F_{1,19}=8.46$, $p=.009$, slope $=1.69[\mathrm{SE}=0.58]$; dichromatic species: $F_{1,17}=20.11, p<.001$, slope $\left.=1.41[\mathrm{SE}=0.31]\right)$.

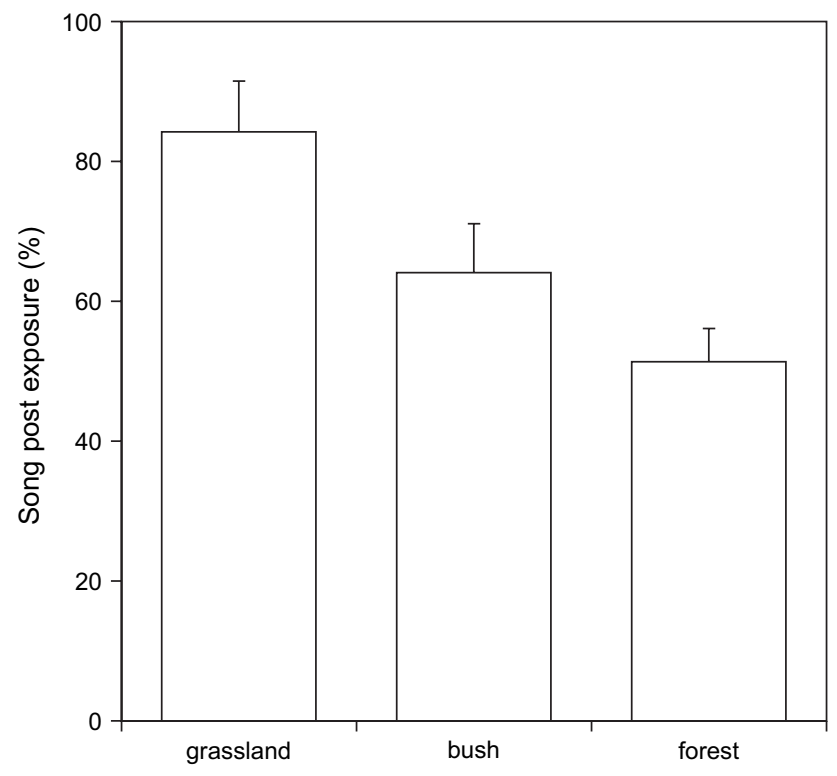

Figure 3

Song post exposure in relation to breeding habitat in 57 species. Columns and error bars (standard errors) correspond to the analysis in which habitat was used as a categorical variable $(n=13$ for grassland species, $n=14$ for bush species, and $n=30$ for forest species).

There was a significant interspecific relationship between song post exposure and habitat type as bird species breeding in grassland or bushes more often sang from exposed posts than forest species (Brunch: $t_{11}=-2.59, p=.025$; Crunch: $F_{1,45}=5.53, p=.028$; Figure 3 ). Using linear contrasts, we created a multivariate model, with prey susceptibility index as the dependent variable and with song post exposure, body mass, squared body mass, brain mass, wing length, heart mass, liver mass, sexual dichromatism, habitat type, hole-nesting habit, and coloniality (all as continuous traits) as independent variables. From this full model of predictor variables, we selected the best set of variables that explain the largest amount of interspecific variance in prey susceptibility. The stepwise procedure resulted in a simple model, in which only song post exposure, habitat type, and sexual dichromatism remained (Table 2). When we entered the two-way interaction terms of these effects, none of them was significant (results not shown). This implies that the slope for the relationship between prey susceptibility index and song post exposure was similar for sexually dichromatic and monochromatic species and also for species breeding in different habitats.

\section{Prey susceptibility and features of song}

The prey susceptibility index was positively related to syllable repertoire size $\left(F_{1,35}=4.61, p=.039\right)$. However, syllable repertoire size was also correlated with song post exposure $\left(F_{1,31}=\right.$ $9.39, p=.005)$. When we controlled for this covariation in a multiple regression model, the relationship between syllable repertoire size and prey susceptibility index was not significant anymore (effect for syllable repertoire size: $t_{29}=-0.44, p=.66$; effect for song post exposure: $t_{29}=3.00, p=.005$ ). This implies that species with more syllable types in their songs appear to become prey of the sparrowhawk only because they also sing from relatively high posts that attracts predators. None of the remaining song traits was related to the prey susceptibility index among species (song duration: $F_{1,34}=$ $0.02, p=.88$; intersong interval: $F_{1,14}=0.15, p=.71$; song 
Table 2

Prey susceptibility index in relation to song post exposure, body mass, squared body mass, brain mass, wing length, sexual dichromatism, heart mass, liver mass, habitat type, hole-nesting habit, and coloniality

\begin{tabular}{|c|c|c|c|}
\hline Variable & Slope (SE) & $t$ & $p$ \\
\hline Song post exposure & $1.44(0.32)$ & 4.45 & $<.001$ \\
\hline Body mass & & Removed & \\
\hline Body mass $^{2}$ & & Removed & \\
\hline Brain mass & & Removed & \\
\hline Heart mass & & Removed & \\
\hline Liver mass & & Removed & \\
\hline Wing length & & Removed & \\
\hline Sexual dichromatism & $0.53(0.13)$ & 4.20 & $<.001$ \\
\hline Habitat type & $0.33(0.12)$ & 2.88 & .007 \\
\hline Hole nesting & & Removed & \\
\hline Coloniality & & Removed & \\
\hline
\end{tabular}

The model is based on a stepwise multiple regression forced through the origin, from which the nonsignificant $(p<.05)$ terms were removed. The model is based on phylogenetic contrasts and has the statistics $F_{3,31}=12.90, r^{2}=.56, p<.001$.

type repertoire size: $F_{1,23}=0.47, p=.50$ ). When we entered the two-way interaction terms between sexual dichromatism and song variables, none of them was significant (results not shown). Therefore, we did not create more complex models with these features of songs.

\section{Path analysis models}

We designed alternative path analysis models to discriminate among alternative causal hypotheses that explain the relationship between a dependent variable and a number of explanatory variables. In a first series of models, we determined relationships from the perspective of the predator, with prey susceptibility being the dependent variable. Prey susceptibility may either be determined by song post exposure and sexual dichromatism independently or song post exposure may interact with sexual dichromatism to affect predation risk (Figure 4). The best-fit model showed that the prey susceptibility index was independently related to song post exposure and sexual dichromatism. However, this model explained only $2 \%$ more of the variance than the alternative model that allowed for covariation between song post exposure and sexual dichromatism (Figure 4). In a second series of analyses, we investigated how from a sexual selection perspective predation risk might affect song post exposure and sexual dichromatism and if covariation between the two song features was independent or caused by predation risk being an intermediary variable. Thus, the secondary sexual characters were the dependent variables in these models. We created two sets of models, where a potential sexual trait (song post exposure or sexual dichromatism) is affected by the other potential sexual trait and prey susceptibility index by considering both independent and correlated evolution (Figure 4). These models generally explained smaller amounts of variance than the above models from the predator perspective (19-31\% compared to 43-45\%). This suggests that the evolutionary scenario that assumes that intense sexual selection may increase the risk of predation is more likely than the opposite causal mechanism that assumes that predation rate affects the expression of sexual traits.

\section{DISCUSSION}

The main result of this study of song and predation in birds was that bird species with the most exposed song posts had the highest risks of predation by the sparrowhawk. Prey susceptibility to predation was stronger in sexually dichromatic species, but song post exposure was independent of sexual dichromatism. There was no significant evidence for vulnerability to predation to increase more with song post exposure in dichromatic as compared to monochromatic species. Song post exposure decreased from grassland over bushes and shrub to forest. Other song traits appeared to be unrelated to prey susceptibility when covariation with song post exposure held constant. Path analysis models revealed that selection acting on sexual dichromatism and song post exposure has a secondary impact for predation risk.

Predation by small avian predators is a main cause of mortality in passerine birds (e.g., Newton, 1986), and predation is therefore likely to impose an important force of selection on the phenotype of all potential prey species. Song post exposure was significantly related to predation risk across species of birds, with a greater level of exposure being found in the most predation-prone species (Figure 1). This result did not differ significantly between sexually monochromatic and dichromatic species. We also included a number of other variables such as habitat, hole nesting, coloniality, brain mass, wing length, and body mass into the statistical analyses but still retained this strong positive relationship between predation susceptibility and song post exposure. If predators preyed on different species relative to their exposure of song posts, we should expect a positive relationship. However, if males changed their song post choice in response to risk of predation, with the species with high susceptibility to predation having the least exposed song posts, we should expect a negative relationship between the two variables. The opposite pattern suggests that selection pressures due to sexual selection or the physical environment are the most important ones. We included habitat as a variable because song posts are higher above the ground in more dense habitats (Scherrer, 1972), but it may also affect the sparrowhawk's choice of prey due to its habitat preference during hunting. However, this did not eliminate the relationship between song post exposure and predation susceptibility. Alternatively, individuals at greater height might assess risks of predation as being smaller than when on the ground. Blumstein et al. (2004) did not find evidence consistent with this expectation because flight initiation distance in different species of birds was unrelated to whether they were close to or well above the ground. Therefore, we suggest that sexual selection caused by greater mating success of males that sing from high song posts either due to attraction of more females or due to a female preference for males using high song posts may account for the association.

Song post exposure is likely to be linked to song features and habitat because habitats may differ in their sound transmission and sound perception properties. While high song posts may not necessarily benefit transmission of song (e.g., Dabelsteen et al., 1993; Holland et al., 1998), they may facilitate perception of sounds. In forests, song posts just below the canopy may be advantageous for long-range communication due to the effects of temperature inversions (Wiley and Richards, 1982). Because different song features have different transmission properties, we should also expect feedback between song post exposure, song feature, and habitat. Previous studies have shown greater attenuation of highfrequency songs in forests than in open habitats (Chappuis, 1971; Morton, 1975 ).

Because song post exposure, sexual dichromatism, and predation risk covaried in a complex way, we attempted to distinguish between several different hypotheses using path analysis as a tool. In a first series of analyses from the perspective of the predator, we found that the prey susceptibility index was independently related to song post exposure and sexual 
Models from the predator's perspective

(a)

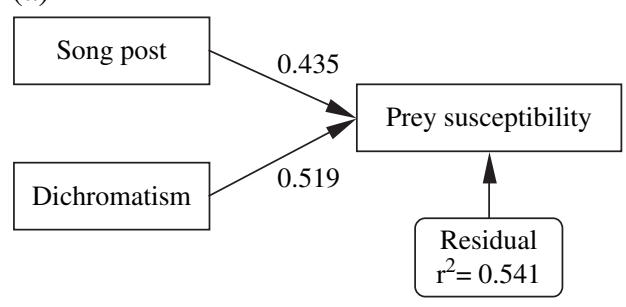

(b)

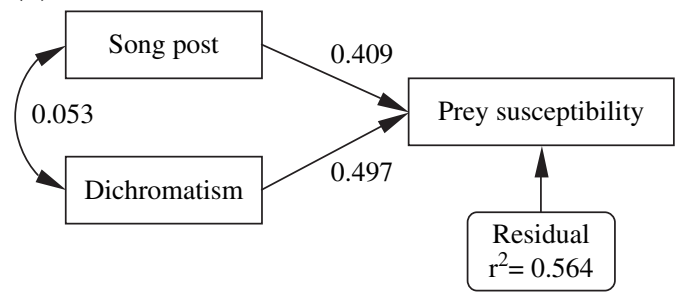

Models from perspective of sexual susceptibility

(c)

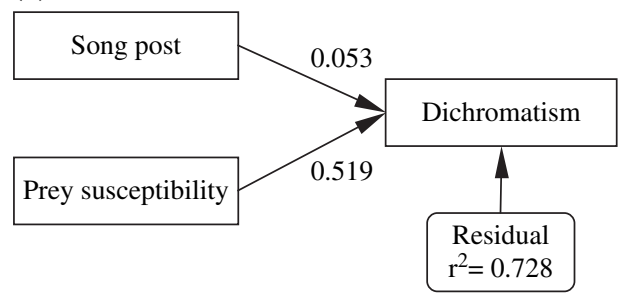

(e)

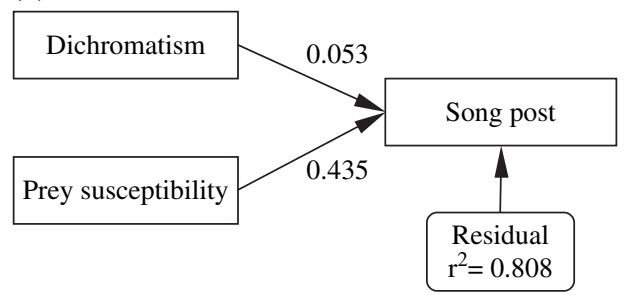

(d)

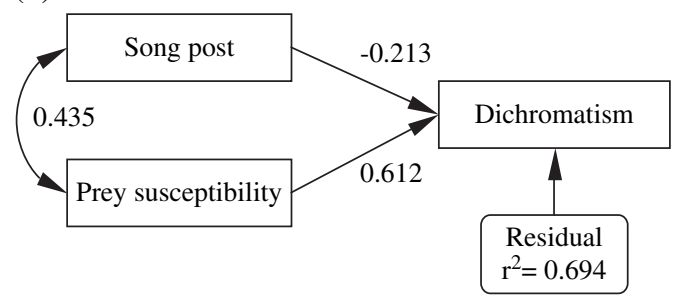

(f)

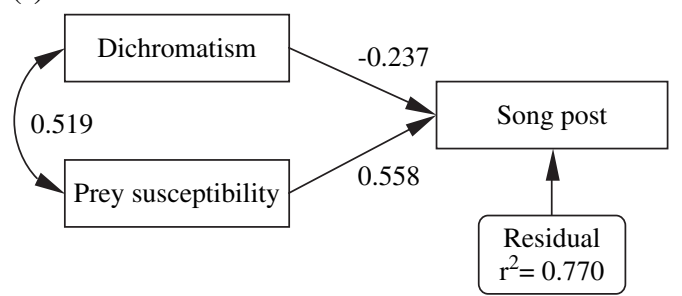

Figure 4

Path analysis models of the relationship between prey susceptibility index, song post exposure, and sexual dichromatism as seen from the perspective of a predator $(\mathrm{a}, \mathrm{b})$ and from a sexual selection perspective $(\mathrm{c}-\mathrm{f})$. Based on the explanatory power, the best-fit models assume that song post exposure and sexual dichromatism affect the prey susceptibility index. Values are path coefficients as determined by the regression coefficients (beta) of the relevant regressions (forced through the origin) of the phylogenetically independent contrasts. Residual variance is the amount of variance that is not explained by the model, while the explained variance can be computed as $1-r^{2}$.

dichromatism. This model explained only $2 \%$ more of the variance than the alternative model that assumed covariation between song post exposure and sexual dichromatism. However, the relationship between song post exposure and sexual dichromatism was generally weak. This suggests that predation caused by the sparrowhawk is independently related to song post exposure and sexual dichromatism. In a second series of analyses from a sexual selection perspective, we found weaker evidence for a sexual character being affected by predation rate as the explanatory power of these models was lower than models from the predator's perspective. This pattern was independent of whether we allowed covariation between the predictor variables. From the path analysis modeling, we conclude that the evolutionary scenario, which predicts that intense sexual selection has a secondary impact on predation rate, is more likely than the opposite causal mechanism in which predation affects sexual selection. Therefore, singing from high song posts and having dichromatic plumage may increase predation rate, but females are unlikely to prefer males with high song post exposure and colorful plumage only because males of such species are better at avoiding predators. The costs associated with these sexual traits that mediate a female preference should be sought among other mechanisms independent of predator pressure.
The evolution of secondary sexual characters is generally determined by both natural and sexual selection to optimize reproductive success under given environmental conditions (Andersson, 1994). These selection pressures may sometimes involve forces that act in opposite directions on trait elaboration. Hence, in such cases the degree of signal expression observed in nature should strike the optimal balance between conflicting pressures for greater efficiency and lower fitness costs (Endler, 1992, 1993; Wiley, 1983, 1992). Here, we provided evidence that the choice for song post that has a potential to reflect male quality (see Ward and Slater, 2004) may be a target of natural selection via increased predation risk.

The results of the present study have important implications for future studies of the costs of sexual selection. We consider that experiments designed to test for the effects of song post exposure and plumage and song characteristics on predation risk would be very informative. For example, we could imagine that a trained hawk could be used to identify and assess the relative importance of features that affect predation risk. Our study shows that song posts are a previously overlooked factor in studies of acoustically based sexual selection and that future studies of the intraspecific and interspecific determinants of song post exposure could help identify factors involved in the optimization of acoustic signaling in birds and other taxa. 
We would like to thank all landowners who provided access to their properties. H. Grunnet and J. K. Jensen helped collect some of the material.

\section{REFERENCES}

Andersson M, 1994. Sexual selection. Princeton: Princeton University Press.

Badyaev AV, Hill GE, Weckworth BV, 2002. Species divergence in sexually selected traits: increase in song elaboration is related to decrease in plumage ornamentation in finches. Evolution 56:412-419.

Barker FK, Barrowclough GF, Groth JG, 2001. A phylogenetic hypothesis for passerine birds: taxonomic and biogeographic implications of an analysis of nuclear DNA sequence data. Proc R Soc Lond B 269:295-308

Bell BD, Borowiec M, Lontkowski J, Pledger S, 2004. Short records of marsh warbler (Acrocephalus palustris) song provide indices that correlate with nesting success. J Ornithol 145:8-15.

Bennett PM, Owens IPF, 2002. Evolutionary ecology of birds. Oxford: Oxford University Press.

Blondel J, Catzeflis F, Perret P, 1996. Molecular phylogeny and the historical biogeography of the warblers of the genus Sylvia (Aves). J Evol Biol 9:871-891.

Blumstein DT, Fernández-Juricic E, LeDee O, Larsen E, RodriguezPrieto I, Zugmeyer C, 2004. Avian risk assessment: effects of perching height and detectability. Ethology 110:273-285.

Bown $\mathrm{CH}, 1982$. Ventroloquial and locatable vocalizations in birds. Z Tierpsychol 59:338-350.

Burnham KP, Anderson DR, 1998. Model selection and inference. New York: Springer

Cade W, 1975. Acoustically orienting parasitoids: fly phonotaxis to cricket song. Science 190:1312-1313.

Chappuis C, 1971. Un example de l'influence du milieu sur les émissions vocales des oiseaux: L'évolution des chants en forêt tropicale. Terre Vie 118:183-202.

Cibois A, Pasquet E, 1999. Molecular analysis of the phylogeny of 11 genera of the Corvidae. Ibis 141:297-306.

Cramp S, Perrins CM, 1985-1994. The birds of the Western Palearctic. Oxford: Oxford University Press.

Cramp S, Simmons KEL, 1979. The birds of the Western Palearctic, vol. II. Oxford: Oxford University Press.

Cucco M, Malacarne G, 1999. Is the song of black redstart males an honest signal of status? Condor 101:689-694.

Dabelsteen T, Larsen ON, Pedersen SB, 1993. Habitat-induced degradation of sound signals: quantifying the effect of communication sounds and bird location on blur ratio, EA, and signal-to-noise ratio in blackbird song. J Acoust Soc Am 93:2206-2220.

Darwin C, 1871. The descent of man and selection in relation to sex. London: Murray.

Dunning JB Jr, 1993. CRC handbook of avian body masses. Boca Raton: CRC Press.

Endler JA, 1992. Signals, signal conditions and the direction of evolution. Am Nat 139:S125-S153.

Endler JA, 1993. Some general comments on the evolution and design of animal signalling systems. Phil Trans R Soc Lond B 340:215-225.

Felsenstein J, 1985. Phylogenies and the comparative method. Am Nat 125:1-15.

Garamszegi LZ, Avilés J, 2005. Brood parasitism by brown-headed cowbirds and the expression of sexual characters in their hosts. Oecologia 143:167-177.

Garamszegi LZ, Eens M, 2004. The evolution of hippocampus volume and brain size in relation to food hoarding in birds. Ecol Lett 7:1216-1224

Garamszegi LZ, Møller AP, 2004. Extra-pair paternity and the evolution of bird song. Behav Ecol 15:508-519.

Garamszegi LZ, Møller AP, Erritzøe J, 2002. Coevolving avian eye size and brain size in relation to prey capture and nocturnality. Proc $\mathrm{R}$ Soc Lond B 269:961-967.

Garamszegi LZ, Møller AP, Erritzøe J, 2003. The evolution of immune defense and song complexity in birds. Evolution 57:905-912.

Garland T Jr, Harvey PH, Ives AR, 1992. Procedures for the analysis of comparative data using phylogenetically independent contrasts. Syst Biol 41:18-32.
Garland T Jr, Ives AR, 2000. Using the past to predict the present: confidence intervals for regression equations in phylogenetic comparative methods. Am Nat 155:346-364.

Garland T Jr, Midford PE, Ives AR, 1999. An introduction to phylogenetically based statistical methods, with a new method for confidence intervals on ancestral states. Am Zool 39:374-388.

Götmark F, 1993. Conspicuous coloration in male birds is favoured by predation in some species and disfavoured in others. Proc R Soc Lond B 253:143-146.

Götmark F, Post P, 1996. Prey selection by sparrowhawks, Accipiter nisus: relative predation risk for breeding passerine birds in relation to their size, ecology and behaviour. Phil Trans R Soc Lond B 351:1559-1577.

Grafen A, 1990. Biological signals as handicaps. J Theor Biol 144: 517-546.

Green R, 1979. Sampling design and statistical methods for environmental biologists. New York: Wiley.

Greig-Smith PW, 1982a. Seasonal patterns of song production by male stonechats Saxicola torquata. Ornis Scand 13:225-231.

Greig-Smith PW, 1982b. Song-rates and parental care by individual male stonechats (Saxicola torquata). Anim Behav 30:245-252.

Grell MB, 1998. Fuglenes Danmark. Copenhagen: Gad.

Güttinger HR, 1977. Variable and constant structures in greenfinch songs (Chloris chloris) in different locations. Behaviour 60:304-318.

Hale AM, 2004. Predation risk associated with group singing in a neotropical wood-quail. Wilson Bull 116:167-171.

Harvey PH, Pagel MD, 1991. The comparative method in evolutionary biology. Oxford: Oxford University Press.

Holland J, Dabelsteen T, Pedersen SB, Larsen ON, 1998. Degradation of wren Troglodytes troglodytes song: implications for information transfer and ranging. J Acoust Soc Am 103:2154-2166.

Iwaniuk AN, Nelson JE, 2003. Developmental differences are correlated with relative brain size in birds: a comparative analysis. Can J Zool 81:1913-1928.

Jones KE, Purvis A, 1997. An optimum body size for mammals? Comparative evidence from bats. Funct Ecol 11:751-756.

Krebs JR, Kroodsma DE, 1980. Repertoires and geographical variation in birdsong. Adv Study Behav 11:143-177.

Kunc H, Amrhein V, Naguib M, 2005. Acoustic features of song categories and their implications for sexual selection in the nightingale (Luscinia megarhynchos). Behaviour (in press).

Lampe HM, Espmark YO, 1994. Song structure reflects male quality in pied flycatchers, Ficedula hypoleuca. Anim Behav 47:869-876.

Li CC, 1975. Path analysis-a primer. Pacific Grove: Boxwood Press.

Marler P, 1955. Characteristics of some alarm calls. Nature 176:6-8.

Martin TE, Badyaev AV, 1996. Sexual dichromatism in birds: importance of nest predation and nest location for females versus males. Evolution 50:2454-2460.

Matessi G, Pilastro A, Marin G, 2000. Variation in quantitative properties of song among European populations of reed bunting (Emberiza schoeniclus) with respect to bill morphology. Can J Zool 78:428-437.

Mlíkovsky J, 1990. Brain size in birds: 4. Passeriformes. Acta Soc Zool Bohemoslov 54:27-37.

Møller AP, 1996. The cost of secondary sexual characters and the evolution of cost-reducing traits. Ibis 138:112-119.

Møller AP, Birkhead TR, 1994. The evolution of plumage brightness in birds is related to extra-pair paternity. Evolution 48:1089-1100.

Møller AP, Christe P, Lux E, 1999. Parasite-mediated sexual selection: effects of parasites and host immune function. Q Rev Biol 74:3-20.

Møller AP, Erritzøe J, Garamszegi LZ, 2005. Covariation between brain size and immunity in birds: implications for brain size evolution. J Evol Biol 18:223-237.

Møller AP, Merino S, Brown CR, Robertson RJ, 2001. Immune defense and host sociality: a comparative study of swallows and martins. Am Nat 158:136-145.

Morton ES, 1975. Ecological sources of selection on avian sounds. Am Nat 109:17-34.

Mota PG, Cardoso GC, 2001. Song organisation and patterns of variation in the serin (Serinus serinus). Acta Ethol 3:141-150.

Mougeot F, Bretagnolle V, 2000. Predation as a cost of sexual communication in nocturnal seabirds: an experimental approach using acoustic signals. Anim Behav 60:647-656.

Mullarney T, Svensson L, Zetterström D, Grant PJ, 2000. The complete guide to the birds of Europe. London: Harper Collins. 
Naguib M, Kolb H, 1992. Comparison of the song structure and succession in the thrush nightingale (Luscinia luscinia) and the blue throat (Luscinia scevica). J Ornithol 133:133-145.

Newton I, 1986. The sparrowhawk. Berkhamstead: Poyser.

Nielsen JT, 2004a. A population study of sparrowhawks Accipiter nisus in Vendsyssel, Denmark, 1977-1997 (in Danish with English summary). Dan Ornitol Foren Tidsskr 98:147-162.

Nielsen JT, 2004b. Prey selection of sparrowhawks in Vendsyssel, Denmark (in Danish with English summary). Dan Ornitol Foren Tidsskr 98:164-173.

Opdam P, 1978. Feeding ecology of a sparrowhawk population (Accipiter nisus). Ardea 66:137-155.

Purvis A, Rambaut A, 1995. Comparative analysis by independent contrasts (CAIC). Comput Appl Biosci 11:247-251.

Read AF, 1987. Comparative evidence supports the Hamilton and Zuk hypothesis on parasites and sexual selection. Nature 328: 68-70.

Read AF, Weary DM, 1992. The evolution of bird song: comparative analyses. Phil Trans R Soc Lond B 338:165-187.

Scherrer B, 1972. Etude sur le poste de chant. Jean-le-Blanc 11:2-46.

Shatler MD, 1978. Localisation of passerine seet and mobbing calls by goshawks and pygmy owls. Z Tierpsychol 46:260-267.

Sheldon FH, Slikas B, Kinnarney M, Gill FB, Zhao E, Silverin B, 1992. DNA-DNA hybridization evidence of phylogenetic relationships among major lineages of Parus. Auk 109:173-185.

Sibley CG, Ahlquist JE, 1990. Phylogeny and classification of birds, a study in molecular evolution. New Haven, London: Yale University Press.

Singer D, Nicolai J, 1990. Organization principles in the song of the woodlark (Lullula arborea). J Ornithol 131:279-290.

Slabbekoorn H, Smith TB, 2002. Bird song, ecology, and speciation. Phil Trans R Soc Lond B 357:493-503.

Slikas B, Sheldon FH, Gill FB, 1996. Phylogeny of titmice (Paridae). I. Estimate of relationships among subgenera based on DNA-DNA hybridization. J Avian Biol 27:70-82.
Sokal RR, Rohlf FJ, 1995. Biometry, 3rd edition. New York: Freeman. Svensson L, 1984. Identification guide to European passerines. Stockholm: L. Svensson.

Székely T, Catchpole CK, DeVoogd A, Marchl Z, DeVoogd T, 1996. Evolutionary changes in a song control area of the brain (HVC) are associated with evolutionary changes in song repertoire among European warblers (Sylviidae). Proc R Soc Lond B. 263:607-610.

Thielcke G, Wüstenberg K, 1985. Experiments on the origin of dialects in the short-toed tree creeper (Certhia brachydactyla). Behav Ecol Sociobiol 16:195-2001.

van Beusekom CF, 1972. Ecological isolation with respect to food between sparrowhawk and goshawk. Ardea 60:72-96.

Von Gerss W, 1989. Estimating the average strophe length of the song of the skylark (Alauda arvensis). Zool Anz 222:27-36.

Ward S, Slater PJB, 2004. The energetic cost of bird song. 2nd European Conference on Behavioural Biology, Groningen, The Netherlands.

Wiley RH, 1983. The evolution of communication: information and manipulation. In: Communication (Halliday TR, Slater PJB, eds). Oxford: Blackwell; 82-113.

Wiley RH, 1992. Errors, exaggeration and deception in animal communication. In: Behavioural mechanisms in evolutionary ecology (Real LA, ed). London: University of Chicago Press; 157-189.

Wiley RH, Richards DG, 1982. Adaptations for acoustic communication in birds: sound transmission and signal detection. In: Acoustic communication in birds (Kroodsma DE, Miller EH, eds). vol. 1. New York: Academic Press; 131-181.

Wright S, 1968. Evolution and the genetics of populations, Vol. 1. Genetic and biometric foundations. Chicago, Illinois: University of Chicago Press.

Zahavi A, 1975. Mate selection-a selection for a handicap. J Theor Biol 53:205-214.

Zuk M, Kolluru GR, 1998. Exploitation of sexual signals by predators and parasitoids. Q Rev Biol 73:415-438. 